\title{
Formação do PNAIC em Geometria e a Trajetória Educacional dos Professores Alfabetizadores*
}

\author{
Formation of the PNAIC in Geometry and the Educational Trajectory of \\ the Literacy Teachers
}

\author{
Aline Pereira Ramirez Barbosa ** \\ ORCID iD 0000-0002-1738-5897 \\ Beatriz Salemme Corrêa Cortela ${ }^{* * *}$ \\ ORCID iD 0000-0002-1821-3106
}

\begin{abstract}
Resumo
Neste artigo apresentam-se a trajetória educacional de cinco professoras alfabetizadoras referentes à aprendizagem em Geometria e como elaboraram suas estratégias de ensino e avaliaram o curso, após terem participado de formação continuada sobre os respectivos conceitos no Pacto Nacional da Alfabetização na Idade Certa (PNAIC). De caráter qualitativo, este trabalho teve como instrumentos de coleta de dados entrevistas semiestruturadas e notas de campo elaboradas durante a observação das aulas. Para a sua análise, foram utilizadas metodologias decorrentes da Análise de Discurso, na linha francesa, visando compreender as condições de produção nas quais esses sujeitos situam-se. Os resultados mostraram que ocorreram lacunas conceituais na formação dessas participantes, bem como os discursos indicaram que os sujeitos sofreram influências do período de abandono ou minimização dos conceitos geométricos em suas formações iniciais e que afetam, ainda hoje, a maneira como compreendem e elaboram o seu fazer docente em relação a essa temática.
\end{abstract}

Palavras-chave: Trajetória Educacional. Ensino de Geometria. PNAIC. Ciclo de Alfabetização.

\begin{abstract}
In this work, we present the educational trajectory of five literacy teachers regarding the learning in Geometry and how, after they participated in the continuous formation of these concepts based on the National Pact of Literacy in the Right Age (PNAIC), they elaborated their teaching strategies and evaluated this course. This work, which is of a qualitative character, had semi-structured interviews and field notes elaborated during class observations as instruments of data collection. For the analysis, we used methodologies resulting from the French Line of the Discourse Analysis aiming to understand the production conditions in which these subjects are situated. Our results showed that there was a conceptual gap in the formation of these participants, and the discourses indicated that
\end{abstract}

* Este trabalho tem por base parte de uma pesquisa de mestrado desenvolvida pela primeira autora (BARBOSA, 2017), tendo como orientadora a segunda autora.

** Mestra em Educação pela Universidade Estadual Paulista "Júlio de Mesquita Filho" (UNESP). Professora dos Anos Iniciais do Ensino Fundamental no município de Bauru, São Paulo e doutoranda do programa Educação para a Ciência da Universidade Estadual Paulista "Júlio de Mesquita Filho" (UNESP), Bauru, São Paulo, Brasil. Endereço para correspondência: Av. Eng. Luiz Edmundo Carrijo Coube, 14-01, Vargem Limpa, Bauru, São Paulo, Brasil, CEP: 17033-360. E-mail: aline_rmz@yahoo.com.br.

*** Doutora em Educação para Ciência pela Universidade Estadual Paulista “Júlio de Mesquita Filho" (UNESP). Docente do Departamento de Educação e do Programa de Pós-Graduação em Educação para Ciência da Universidade Estadual Paulista "Júlio de Mesquita Filho" (UNESP), Bauru, São Paulo, Brasil. Endereço para correspondência: Av. Eng. Luiz Edmundo Carrijo Coube, 14-01, Vargem Limpa, Bauru, São Paulo, Brasil, CEP: 17033-360. E-mail: biacortela@fc.unesp.br. 
they were influenced by the abandonment or minimization of geometric concepts, affecting how they currently understand and elaborate their teaching work in relation to this topic.

Keywords: Educational trajectory. Geometry Teaching. PNAIC. Literacy Cycle.

\section{Introdução}

O ensino de Geometria para os Anos Iniciais do Ensino Fundamental ( $1^{\circ}$ ao $3^{\circ}$ anos), também chamado ciclo de alfabetização, voltou a ganhar destaque nas discussões acadêmicas, após a implantação dos Parâmetros Curriculares Nacionais (PCN), no ano de 1997. Pesquisas sobre essa temática vêm sendo realizadas há mais de duas décadas e autores como Fonseca et al. (2002); Lorenzato (2010); Nacarato (2000); Pavanello, (1993); Pirola, (1995), entre outros, sinalizaram que o ensino desses conteúdos atrelados ao ciclo de alfabetização ficou relegado a um segundo plano, em decorrência, principalmente, de três fatores: o primeiro refere-se ao fato de o enfoque nessa fase da escolarização ser voltado ao ensino da língua materna; segundo refere-se as lacunas formativas dos professores em relação aos conteúdos de Geometria; e o terceiro à predominância de práticas tradicionais de ensino de Geometria, que consideram apenas a memorização das formas geométricas e classificação dos sólidos, por exemplo.

Frente a essas e outras problemáticas, em relação ao ensino de Matemática para o ciclo de alfabetização (Anos Iniciais do Ensino Fundamental), no ano de 2014, um programa de formação continuada de professores, denominado Pacto Nacional da Alfabetização na Idade Certa (PNAIC), propôs momentos formativos sobre os conteúdos geométricos, distribuídos em doze horas, visando a subsidiar reflexões, estudos teóricos e novas possibilidades práticas sobre eles.

A primeira autora, que também atua como alfabetizadora, participou do PNAIC de Matemática, em 2014, e percebeu, ao longo desse processo, as inúmeras dúvidas apresentadas pelas professoras cursistas, principalmente em relação ao eixo temático Espaço e Forma Geometria. Tais dúvidas despertaram seu interesse em pesquisar para compreender por que as professoras manifestaram dificuldades com esses conteúdos, buscando analisar se após o curso, essas teriam sido superadas.

Vigente desde 2012, o PNAIC tem por objetivo alfabetizar, sob a perspectiva do letramento, alunos com até oito anos de idade e que estejam cursando o terceiro ano do Ensino Fundamental - Anos Iniciais. É decorrente de uma parceria entre o Ministério da Educação (MEC) e as secretarias estaduais, distritais e municipais de educação que, juntas, elaboram ações de formação continuada para os professores, a fim de promover reflexões teóricas e 
práticas necessárias para que as metas educacionais de alfabetização na idade certa sejam alcançadas.

Esta pesquisa objetivou dar voz a cinco sujeitos que participaram da formação do PNAIC, em 2014, e que lecionavam para os Anos Iniciais, no ano de 2016. A ideia foi ouvir, observar e registrar quais foram os impactos da formação continuada do PNAIC em suas ações, além de buscar compreender como ocorreu a formação em Geometria ao longo do próprio processo de escolarização (do Ensino Fundamental até a Graduação).

Objetiva-se neste artigo, primordialmente, relatar a trajetória educacional desses sujeitos em relação à aprendizagem de Geometria e como esses conhecimentos, ou a ausência deles, apresentaram-se refletidos no chão da sala de aula, ou seja, os sentidos dados por esses docentes e as marcas das formações recebidas.

Para analisar os dados coletados, buscou-se embasamento na linha teórica da Análise de Discurso (AD), na perspectiva francesa de Pêcheux, pois se compreende que esse referencial fornece o entendimento de elementos que possibilitam identificar a relação entre sujeito, linguagem, ideologia e história.

\section{O ensino de Geometria sob a perspectiva do letramento: a formação do PNAIC}

Por alfabetização, os textos do PNAIC consideram a compreensão do funcionamento do sistema de escrita, da fluência da leitura e o domínio de estratégias de compreensão de textos escritos e da produção textual dentro da perspectiva do letramento. A alfabetização matemática, em consonância com o material de formação de linguagem, “[...] é entendida como um instrumento para a leitura do mundo, uma perspectiva que supera a simples decodificação dos números e a resolução das quatro operações básicas” (BRASIL, 2014, p. 5).

Norteado por essa diretriz, o curso de formação continuada em Geometria, oferecido pelo PNAIC, enfocou nas doze horas destinadas ao ensino dessa temática, possibilidades de articulação desses conceitos com outras áreas do saber, buscando favorecer reflexões teóricas necessárias ao entendimento da Geometria e oferecendo sugestões didáticas que subsidiariam o fazer docente.

Entender a alfabetização Matemática na perspectiva do letramento impõe o constante diálogo com outras áreas do conhecimento e, principalmente, com as práticas sociais, sejam elas do mundo da criança como jogos e brincadeiras, sejam elas do mundo do adulto e de perspectivas diferenciadas, como aquelas das diversas comunidades que formam o campo brasileiro (BRASIL, 2014, p. 15).

Sobre essa perspectiva, Mandarino (2014) justifica a pertinência do estudo de 
Geometria, a partir de duas considerações relevantes: a primeira, porque está presente no dia a dia e acontece de acordo com o desenvolvimento cognitivo e social da criança, desde o nascimento, com o reconhecimento do espaço ao redor, até a realização e descrição de deslocamentos, o que exige competências geométricas mais complexas; em segundo lugar, devido à importância histórica da Geometria, desde as primeiras fases do desenvolvimento do saber matemático.

Logo, o ensino de Geometria possibilita a união dos conhecimentos que antecedem o acesso à escola e o conhecimento sistematizado por ela, permitindo compreender que " [...] as experiências prévias precisam servir como elementos de referência para o professor organizar atividades que contribuam para, aos poucos, dar significação aos conceitos matemáticos" (MANDARINO, 2014, p. 10). Além do mais, o estudo da Geometria facilita as percepções espaciais dos estudantes, contribuindo para uma melhor apreciação das construções e dos trabalhos artísticos, tanto dos seres humanos quanto da natureza (FONSECA et al., 2002).

Segundo o PCN de Matemática (BRASIL, 1997), o ensino de Geometria pode e deve ser trabalhado de forma interdisciplinar, relacionando-se às disciplinas de Arte, Geografia, Astronomia, entre outras. Na disciplina de Matemática, os conceitos geométricos são subsídios para o entendimento de outros conteúdos, entre eles a trigonometria, a resolução de problemas, a compreensão de grandezas e medidas e, nos Anos Iniciais, “[...] contribui para a aprendizagem de números e medidas, pois estimula a criança a observar, perceber semelhanças e diferenças, identificar regularidades e vice-versa" (BRASIL, 1997, p. 39).

De acordo com o documento Direito de Aprendizagem da Área de Matemática (BRASIL, 2012), que embasou a formação do PNAIC, dois objetivos devem ser alcançados com as turmas de alfabetização, no que diz respeito à Geometria: construir noções de localização e movimentação no espaço físico, para a orientação espacial em diferentes situações do cotidiano, e reconhecer figuras geométricas.

Lorenzato (1995) justifica a necessidade de a Geometria ser ensinada na escola, argumentando que sem as habilidades oriundas destes conhecimentos, as pessoas não desenvolvem o pensamento geométrico e que, sem essas habilidades, “[...] não poderão se utilizar da Geometria como fator altamente facilitador para a compreensão e resolução de questões de outras áreas de conhecimento humano" (LORENZATO, 1995, p. 5). Ainda segundo o autor, o conhecimento da Geometria possibilita a leitura interpretativa do mundo, pois permite comunicar ideias, estimular o raciocínio e resolver problemas.

O curso de Geometria do PNAIC pautou-se nestas perspectivas e nele foram discutidos textos e exemplificações de atividades elaboradas por doze autores de diferentes áreas 
relacionadas à Educação Matemática. As formações foram oferecidas por orientadoras de estudos, que também atuavam como professoras alfabetizadoras, selecionadas pela Secretaria Municipal de Educação para receberem as orientações e ensinamentos de conceitos ministrados por docentes universitários e pesquisadores da área, repassando-os às professoras cursistas. Estas, por sua vez, receberam um caderno destinado à formação em Geometria, que abordou oito subconteúdos em seus textos e orientações didáticas: 1. Dimensão, Semelhança e Forma; 2. A Geometria e o ciclo de alfabetização; 3. Primeiros Elementos da Geometria; 4. Conexões da Geometria com a Arte; 5. Materiais Visuais para o Ensino da Geometria; 6. Localização e Movimento; 7. Cartografias e Lateralidade e 8. Modos de ver e Representar.

Nesse curso de formação continuada, a expectativa era que, ao se abordar as questões do ensino de Geometria amparados em teoria e em sugestões de estratégias didáticas disponibilizadas nos cadernos de formação, exemplificações de atividades, vídeos, livros paradidáticos com o tema, entre outros, os professores pudessem ampliar seus conhecimentos geométricos e ensinar além do que o já percebido em pesquisas anteriores: “[...] memorização de nomes de figuras e propriedades geométricas, sem conexões com outras áreas da Matemática e outros campos do saber" (PIROLA, 1995, p. 16).

Contudo, observa-se que a trajetória educacional dos sujeitos em relação à Geometria é um fator importante a se considerar nesse processo, tendo em vista que é consenso entre os pesquisadores Fonseca et al. (2002); Lorenzato (2010); Nacarato (2000); Pavanello (1993); Pirola $(1995,2014)$, entre outros, que o ensino de Geometria não tem destaque no ensino de Matemática, principalmente nos Anos Iniciais do Ensino Fundamental. Segundo eles, tal fato relaciona-se a vários fatores, um deles a falta de preparo dos professores em ensinar tais conteúdos, pois, como será apresentado mais adiante, o processo de escolarização que esses sujeitos vivenciaram, deixaram lacunas referentes aos conteúdos geométricos e estas influenciam a forma como ensinam.

\section{Quem, onde e por quê: os aspectos metodológicos}

Conforme mencionado anteriormente, este artigo é um recorte de dissertação de mestrado (BARBOSA, 2017) de caráter qualitativo (BOGDAN; BIKLEN, 1994), devido ao fato de esta vertente possibilitar o questionamento dos sujeitos, de modo que percebam como experienciam em suas práticas docentes, como interpretam suas experiências e como se estruturam ao ensinar.

Entre as 97 escolas que atendem ao Ensino Fundamental, na cidade de Bauru/SP, 
dezesseis pertencem ao sistema municipal de ensino, trinta e três à rede particular e quarenta e oito à rede estadual. Dentre as dezesseis escolas municipais, foram selecionadas duas para participarem desta amostra. Ambas estão situadas em bairros periféricos e são consideradas regiões carentes, cuja população, em sua maioria, é composta por trabalhadores do setor terciário que recebem benefícios governamentais, como, por exemplo, Bolsa Família. O critério adotado para a escolha foi o Índice de Desenvolvimento da Educação Básica (IDEB) dessas escolas, que são classificados como baixos, se comparados às demais do município. Por esses motivos, ações formativas promovidas pela Secretaria Municipal de Educação são constantemente realizadas, visando à elevação desses índices.

Os sujeitos desta pesquisa foram cinco professoras, com idades entre trinta e quarenta anos e com tempo de magistério compreendido entre oito e dezesseis anos. Lecionam, em média, há dez anos no sistema municipal de ensino de Bauru, participaram da formação em Geometria do PNAIC no ano de 2014 e atuavam como professoras dos Anos Iniciais, em 2016.

A primeira forma de coleta de dados foi uma entrevista semiestrurada, que durou em média vinte minutos, abordando questões que possibilitaram levantar dados referentes à formação profissional acadêmica, até a formação específica no que diz respeito aos conceitos geométricos e sua relação com o ensino, totalizando vinte e uma questões. Apresentam-se, no Quadro 1, os blocos temáticos, objetos de estudo deste artigo, e que se referem às questões sobre a aprendizagem dos sujeitos em relação à Geometria, à compreensão sobre a dificuldades com o ensino desses conteúdos e a avaliação sobre a formação recebida no PNAIC.

\begin{tabular}{|l|l|}
\hline $\begin{array}{l}\text { A) Formação do educador } \\
\text { em Geometria: }\end{array}$ & $\begin{array}{l}\text { 1- Considerando sua trajetória educacional (do Ensino Fundamental até o } \\
\text { Ensino Médio), como foi sua aprendizagem em relação aos conteúdos de } \\
\text { Geometria? E na graduação? } \\
\text { 2- A formação obtida foi suficiente para subsidiar o processo de ensino desses } \\
\text { conteúdos em nível fundamental? Por quê? }\end{array}$ \\
\hline B) Ensino de Geometria & 3- O que espera que seu aluno aprenda sobre Geometria? \\
\hline $\begin{array}{l}\text { C) Formação em geometria } \\
\text { do PNAIC }\end{array}$ & $\begin{array}{l}\text { 4- Como avalia a formação em Geometria oferecida pelo PNAIC? } \\
\text { 5- Como você avalia sua participação e aproveitamento na formação em } \\
\text { Geometria do PNAIC? Justifique. }\end{array}$ \\
\hline & Quadro 1 - Formação e ensino de Geometria
\end{tabular}
Fonte: BARBOSA (2017).

A entrevista foi realizada de maneira linear, ou seja, mesmo que os sujeitos tivessem mencionado possíveis respostas às perguntas subsequentes, manteve-se este padrão, visando à certeza de obter e captar possíveis modificações nas respostas, ao longo do processo. Posteriormente, foram realizadas as transcrições das falas e incluídas as anotações de campo sobre os fatos ocorridos nos momentos das entrevistas, como demonstração de sentimentos, pausas, entre outros. Esses fatores são importantes para os registros, tendo em vista o referencial de análise adotado: AD, na linha francesa, fundamentada em Orlandi $(2002,2016)$. 
Para assegurar o anonimato das participantes combinou-se, ao assinar o Termo de Aceite, que elas seriam identificadas, no texto pela letra $P$ (Professora), seguida por um número que, sob a forma de índice, indicaria a ordem de participação nas entrevistas, sendo o primeiro sujeito denominado $\mathrm{P}_{1}$ e o último sujeito $\mathrm{P}_{5}$.

A segunda forma de coleta de dados foi o acompanhamento das aulas que as professoras dedicaram ao ensino de Geometria. Todas as entrevistadas aceitaram dar continuidade à pesquisa e se envolver no estudo de caso. Assim, foi agendado, em dia e horário mais conveniente às professoras, um momento para que a pesquisadora estivesse presente em suas aulas. Nesse momento, foi realizada uma observação participada, que também pode ser designada de " [...] entrevista acção, pois se insere dentro da acção que se desenvolve e constitui um processo de recolha de dados que se situa entre entrevista e a acção" (ESTRELA, 1994, p. $35)$.

Assim, de posse dos aportes teóricos da Análise de Discurso (AD), a pesquisadora realizou as análises e encontrou indicativos nas falas e ações dos sujeitos que possibilitaram identificar as problemáticas envolvendo a trajetória com a aprendizagem dos conceitos geométricos e, consequentemente, o ensino desses conteúdos para os Anos Iniciais, bem como buscar traços da formação em Geometria do PNAIC em seus planejamentos e atuações em sala de aula.

\section{A análise de discurso como aporte teórico- metodológico}

Para realizar as análises dos dados deste estudo foram utilizadas as noções da Análise de Discurso (AD), na vertente francesa, desenvolvida no Brasil pelos trabalhos de Orlandi (2002, 2016) e Brandão (2002). Defende-se que esse referencial fornece o entendimento de elementos que possibilitam compreender a relação entre sujeito, linguagem, ideologia e história.

Orlandi (2002) define discurso como efeito de sentidos entre locutores, uma vez que a ocorrência de um discurso não se trata apenas de uma transmissão linear de informação. Para $\mathrm{AD}$, o discurso "[...] dá ideia de em curso-do, percurso-de, correr, pôr em movimento" (ORLANDI, 2002, p. 15). Ou seja, considera a palavra em movimento, o sujeito falando; a linguagem como mediação necessária entre o homem e a realidade natural e social.

Assim, a autora supracitada indica que a AD trabalha com o significado da língua de forma abstrata, com as diferentes formas de significar que o homem lhe atribui. Considera os processos e as condições de produção da linguagem, pela análise das relações estabelecidas 
pela língua com o enunciador e seu contexto de produção. $\mathrm{O}$ analista de discurso busca relacionar a linguagem ao contexto do sujeito, para encontrar regularidades.

Nesse sentido, sob a perspectiva da AD, é preciso problematizar o que se diz, e isto pode ser realizado a partir da interpretação de dois componentes essenciais a esta teoria: o primeiro são os interdiscursos, retomando o que já foi dito antes, em outro lugar, numa outra condição, pois, segundo a autora, “[...] o dizer não é propriedade particular. As palavras não são só nossas. Elas significam pela história e pela língua" (ORLANDI, 2002, p. 32). O segundo aspecto, como já mencionado acima, referem-se às condições de produção, nas quais as interpretações sobre os dados coletados implicam em “[...] buscar determinar as condições de produção dos dizeres e os efeitos de sentido produzidos [...]" (ALMEIDA, 2007, p. 120).

Os discursos estão em constante processo e, ao surgirem, os sujeitos inserem-se neles. A língua e a história afetam os sujeitos provocando a relação de sentidos. Os sujeitos "esquecem" o que foi dito, para se identificar com o que dizem: “[...] é assim que eles se significam retomando palavras já existentes como se elas se originassem neles, e é assim que sentidos e sujeitos estão sempre em movimento, significando de muitas e variadas maneiras" (ORLANDI, 2002, p. 36).

Logo, formação discursiva é aquilo que determina o que pode e o que deve ser dito: o local onde se constrói o sentido. Diante disso, o analista deve compreender a condição de produção daquilo que foi dito, e que as palavras produzidas num determinado contexto histórico possuem posições ideológicas, ou seja, a palavra não tem um sentido por si mesma: ela muda de sentido dependendo da posição daquele que dela faz uso e das posições ideológicas colocadas em jogo.

Com o material de pesquisa coletado (as entrevistas transcritas, as notas elaboradas durante as observações das aulas de Geometria) fez-se uma primeira análise, através de leituras minuciosas, com levantamento das regularidades presentes nos textos. Conforme corrobora Cortela (2011, p. 129), o intuito foi verificar “[...] quem disse, o quê disse, como disse, buscando pistas que explicitem como o discurso está contextualizado, uma vez que seus autores deixam vestígios no fio do discurso".

Ao compreender a trajetória educacional dos sujeitos em relação à aprendizagem de Geometria, durante todo o processo de escolarização, e visualizar este ensino, durante as aulas por eles ministradas, a AD fez-se presente e permitiu identificar as condições do processo de produção discursiva, identificando alguns pontos para reflexão e mudanças, no tocante à formação com o emprego dos conteúdos geométricos. 


\section{0 aprendizado de Geometria do Ensino Fundamental à Graduação: a trajetória dos sujeitos}

Quando questionados sobre a trajetória educacional com os conhecimentos em Geometria (sejam estes nos níveis Fundamental, Médio ou Graduação), foi unânime o fato de os sujeitos declararem não possuírem domínio do conteúdo, ocasionado por um ensino deficiente nessa temática. O Quadro 2 sintetiza as memórias dos sujeitos sobre seus aprendizados, em relação à Geometria.

\begin{tabular}{|c|l|l|}
\hline Sujeitos & \multicolumn{1}{|c|}{ Geometria nos níveis Fundamental e } & Geometria na Graduação \\
\hline $\mathrm{P}_{1}$ & Atividades que envolviam régua e dobraduras. & Nenhuma \\
\hline $\mathrm{P}_{2}$ & $\begin{array}{l}\text { Atividades teóricas, nenhuma atividade prática. } \\
\text { Recorda-se da abordagem destes conteúdos em } \\
\text { aulas de Educação Artística na qual tinha que } \\
\text { desenhar as formas geométricas. }\end{array}$ & $\begin{array}{l}\text { Lembra-se da aula de metodologia da } \\
\text { Matemática, mas nada que destacasse } \\
\text { suas lembranças sobre Geometria. }\end{array}$ \\
\hline $\mathrm{P}_{3}$ & $\begin{array}{l}\text { Atividades trabalhadas no final do ano letivo de } \\
\text { forma superficial; no curso de magistério do } \\
\text { CEFAM não havia muitas atividades. }\end{array}$ & $\begin{array}{l}\text { No curso de Matemática aprendeu } \\
\text { conceitos sobre Geometria e no curso } \\
\text { de Pedagogia não aprendeu nada. }\end{array}$ \\
\hline $\mathrm{P}_{4}$ & $\begin{array}{l}\text { A Geometria sempre foi deixada para o final do } \\
\text { ano e os conhecimentos sobre os conteúdos foram } \\
\text { vagos. }\end{array}$ & $\begin{array}{l}\text { Na Graduação não teve o ensino } \\
\text { destes conteúdos, o curso focou-se } \\
\text { mais nas questões didáticas. }\end{array}$ \\
\hline $\mathrm{P}_{5}$ & $\begin{array}{l}\text { Era o último conteúdo trabalhado no ano letivo, } \\
\text { sempre deixado para o final do ano. }\end{array}$ & $\begin{array}{l}\text { Na Graduação teve alguns } \\
\text { fundamentos da } \\
\text { Matemática, } \\
\text { aprendeu sobre Tangram e polígonos, } \\
\text { mas julga que eles foram superficiais. }\end{array}$ \\
\hline
\end{tabular}

Quadro 2 - Trajetória educacional dos sujeitos sobre sua aprendizagem com os conteúdos Geométricos Fonte: BARBOSA (2017).

Estes dados confirmam apontamentos já comprovado por pesquisas, como em Fonseca et al. (2002), Passos e Nacarato (2014), Pirola (1995), de que, quando em situações de aprendizagem, estes profissionais estiveram submetidos a uma forma de ensino que pouco explorava esses conteúdos, uma vez que, geralmente, eram relegados às últimas páginas dos livros didáticos ou introduzidos, de forma aligeirada, nos últimos dias dos bimestres. Desta forma, a aprendizagem ficou comprometida, implicando em uma maior dificuldade com seu ensino.

Brandão (2002, p. 12) afirma que "[...] a linguagem é lugar de conflito, de confronto ideológico, não podendo ser estudada fora da sociedade, uma vez que os processos que a constituem são histórico-sociais". Nesse sentido, os discursos dos sujeitos demonstraram a condição de produção de ensino a que estiveram submetidos e que foram produzidos entre as décadas de 1950-1960, quando seus professores foram formados. Período em que ocorreram inúmeros encontros e discussões sobre novas propostas de inserção e metodologia de conteúdos matemáticos, amparados pela filosofia da Matemática Moderna, e que causaram ao ensino de 
Geometria uma série de modificações, entre elas, a inclusão no currículo de outras abordagens diferentes da visão euclidiana, em vigor.

Como não houve uma formação específica para o professor daquela época, sobre essa nova forma de ensinar, muitos educadores, sentindo-se inseguros em ensinar Geometria, deixaram de inclúi-la em seus planejamentos. Os que continuaram faziam-no de modo precário. Os próprios livros didáticos traziam, à época, os conteúdos geométricos para os capítulos finais e davam à Álgebra um papel de destaque.

Outro fator relevante é o entendimento de que as lacunas formativas dos sujeitos, referentes ao ensino de Geometria, não foram sanadas, mesmo com o ensino na Graduação. Ou seja, uma formação inicial, onde os profissionais poderiam ou deveriam aprofundar-se ou retomar conceitos importantes sobre Geometria, não foi realizada. Nesse sentido,

É preciso que a formação docente propicie a eles a oportunidade de refazer o percurso de aprendizagem que não foi satisfatoriamente realizado na educação básica para transformá-los em bons professores, que no futuro contribuirão para a melhoria da qualidade da educação básica (MELLO, 2000, p. 102).

Tal afirmação evidencia que a formação inicial de professores constitui-se um dos pontos principais para melhorar a qualidade do ensino, uma vez que "[...] ninguém facilita o desenvolvimento daquilo que não teve oportunidade de aprimorar em si mesmo. Ninguém promove a aprendizagem de conteúdos que não domina [...]” (MELLO, 2000, p. 102).

Desta maneira, com dificuldades conceituais arrastadas por décadas de ensino, fica difícil para um curso de formação continuada suprir os obstáculos deixados. Gatti (2008, p.68) lança ainda uma possível solução, em longo prazo:

[...] não seria melhor investir mais orçamento público para a ampliação de vagas em instituições públicas para formar licenciados e investir na qualificação desses cursos, em termos de projeto, de docentes, de infraestrutura, deixando para a educação continuada realmente os aperfeiçoamentos ou especializações?

Enquanto a formação continuada prosseguir de forma fragmentada e paliativa, visando a suprir lacunas ou atender a demandas locais, os resultados delas oriundos não atingirão um dos fins principais da educação, qual seja "[...] ensinar às novas gerações o conhecimento acumulado e consolidar valores e práticas coerentes com nossa vida civil” (GATTI, 2010, p. 1375). Faz-se necessário integrar essa formação em currículos articulados e voltados a esse objetivo. Neste sentido, coaduna-se com as ideias de Orlandi (2016), ao diferenciar formação e capacitação.

Desse modo, podemos afirmar que educar não é capacitar, nem treinar, nem informar, mas dar condições para que, em seu modo de individuação pelo Estado, o sujeito tenha a formação (conhecimento) necessária para poder constituir-se em uma posiçãosujeito que possa discernir e reconhecer os efeitos de sua prática na formação social de que faz parte [...] (ORLANDI, 2016, p. 74). 
Quando as professoras foram questionadas sobre a aprendizagem de conceitos e metodologias de ensino relacionadas à Geometria na Graduação, foram unânimes em afirmar que os conhecimentos adquiridos não foram suficientes para subsidiar o preparo de aulas para os Anos Iniciais.

$P_{1}$ : Justamente porque eles não ensinaram, não ensinaram a prática mesmo, nem a teoria. Na Pedagogia, por exemplo, eu não tive nenhuma matéria que falasse sobre a importância da Geometria $[\ldots]$

$P_{2}$ : Não, muito fraco. São coisas que a gente tem que correr atrás, para conseguir ensinar uma criança $[\ldots]$

$P_{3}$ : [...] Agora do $1^{o}$ ano até o $5^{\circ}$ ano, pensando na Pedagogia, foi uma formação muito superficial e sem base [...]

$P_{4}$ : Não. Por isso que eu me interessei pelo PNAIC para acrescentar e ser trabalhado naquilo que não me foi trabalhado.

$P_{5}$ : Não, eu aprendi mesmo trabalhando, aprendi dando aula para o quarto e quinto ano, no Estado. Ai que eu fui aprender mesmo a Geometria [...]

(Entrevista cedida a Barbosa, 2017)

Tais respostas indicam que os sujeitos, partindo de sua realidade educacional, buscam meios de sanar as dificuldades encontradas com o ensino de Geometria de diversas formas: participando de cursos de formação continuada, realizando estudos a partir da demanda de trabalho, entre outros. Ressalta-se que, sobre o entendimento da $\mathrm{AD}$, ao buscarem por conta própria os conceitos que julgaram necessários ao ensino, fizeram-no partindo, também, de suas ideologias e sob a influência das diferentes marcas de concepções de ensino, às quais tiveram acesso ao longo de suas formações. Esse conjunto de fatores, somados à formação continuada do PNAIC, promoveram, ou não, novas atitudes em relação ao ensino de Geometria, que serão expostas a seguir.

\section{Eis o ensino: compreendendo o que ficou após o PNAIC}

Visto que a ação pedagógica deve ser espaço privilegiado nas pesquisas, uma vez que é um saber efetivamente específico à classe profissional e direciona o tipo de ação em sala de aula (GAUTHIER et al., 2006), fez-se necessário compreender se e como a formação do PNAIC, em Geometria, influenciou nas abordagens em relação ao ensino desse conteúdo, mesmo com as lacunas formativas expostas nesta pesquisa.

Para que os sujeitos expressassem aquilo que objetivavam e ensinavam em suas aulas (de acordo com a série que lecionavam), foi solicitado que versassem sobre o que desejariam que seus alunos aprendessem, em relação à Geometria.

$P_{1}$ : Poxa, olha, assim, não apenas o que todo mundo dá: formas geométricas, né?! Porque antes do PNAIC, quando falava em Geometria todo mundo já pensava na forma geométrica e hoje 
eu vejo que não, então assim a Geometria tá no dia a dia, então assim localização, movimentação no espaço [...]

(Entrevista cedida ao autor 1, 2017)

A questão de ir além das conceituações de formas geométricas foi um fator recorrente nas respostas dos outros sujeitos, além do fato de que esperavam que seus alunos "[...] reconheçam as formas geométricas, assim... no concreto" $\left(\mathrm{P}_{2}\right)$; quesaibam "[...] a utilização dela $[. .$.$] " \left(\mathrm{P}_{4}\right)$; e que os alunos consigam "[...] entender e saber o que ele está olhando" $\left(\mathrm{P}_{5}\right)$ (Entrevistas cedidas ao autor 1, 2017).

Quando questionada a pensar sobre o que esperava que seus alunos aprendessem sobre Geometria, ou seja, os objetivos de suas aulas, $\mathrm{P}_{2}$ apresentou suas dificuldades:

$P_{2}$ : Vixi, agora você me pegou. Vou lembrar do quarto ano que era do ano passado. Ano passado tinha que dar cubo, paralelepípedo, as arestas, as vértices, tinha uma parte mais prática que era formar os desenhinhos lá... as figuras geométricas; a parte de quadradinho lá... Como chama?! Malha geométrica! Tinha tudo isso.

(Entrevista cedida ao autor 1, 2017)

Cabe lembrar que esse sujeito lecionava, em 2016, para o $1^{\circ}$ ano do ciclo de alfabetização. No entanto, sentia dificuldade em relacionar os objetivos a essa série de ensino, pois mesmo estando no final de março/2016 (meio do $1^{\circ}$ bimestre), $\mathrm{P}_{2}$ informou "Nossa [risos] nem fiz nada de Geometria ainda para eles [1 ${ }^{\circ}$ ano]. Nem fiz a matemática direito" (Entrevista cedida ao autor 1, 2017). Então, mesmo de posse do entendimento de que o ensino de Geometria por muito tempo foi relegado e minimizado e, após ter participado da formação do PNAIC, a professora demonstrou em sua fala suas intencionalidades com o ensino dessa temática e ainda reproduziu a mesma problemática apontada nas pesquisas, ou seja, o ensino de Geometria continua relegado a um segundo plano em seu planejamento.

No intuito de provocar maiores reflexões, solicitou-se à $\mathrm{P}_{2}$ que explicitasse os objetivos do ensino para a série atual em que atua $\left(1^{\circ}\right.$ ano):

$P_{2}$ : Mas acho que vai ser alguma coisa assim, vamos olhar o livro, ele tem qual formato, ele é quadrado? Ele é triângulo? Vamos pensar onde é que tem uma coisa circular, um círculo na nossa vida? Ai o sol é um círculo? O sol é um quadrado? Bem prático.

(Entrevista cedida ao autor 1, 2017)

$\mathrm{O}$ discurso de $\mathrm{P}_{2}$ indicou suas dificuldades didáticas com a abordagem de conceitos geométricos. Estas dificuldades foram verbalizadas durante a entrevista: “[...] não é uma área que eu me sinta segura, para falar para explicar. Eu não tenho essa segurança toda, não! Falar coisas erradas, aí é círculo... tá bom. Não vou falar bola. É circulo ou uma circunferência?" (Entrevista cedida ao autor 1, 2017).

Dentre as dificuldades apresentadas por $\mathrm{P}_{1}$, a mesma declarou: "[...] tenho que estudar 
antes, não dá para chegar na hora, abrir o livro e dar aula [...]" (Entrevista cedida ao autor 1, 2017). Continuando sua fala, a professora indicou:

$P_{1}$ : [...] tenho muita dificuldade de noção de espaço [...] até mesmo assim, coisa simples, direita e esquerda, às vezes eu tenho que pegar e me policiar para estar ensinando a forma espelhada para eles, mas assim, por enquanto foram dificuldades simples, por eles serem alunos menores né?!

(Entrevista cedida ao autor 1, 2017)

Como já explicitado, os sujeitos desta pesquisa demonstraram, em seus discursos, as condições de produção nos quais foram produzidos. Devido aos relatos das participantes, concluímos que, provavelmente, vivenciaram seus estudos anteriormente às orientações sobre o ensino de Geometria proposto pelo PCN de Matemática (BRASIL, 1997), pois, conforme afirmou $\mathrm{P}_{1}$, apresentaram lacunas formativas, principalmente no que se refere à habilidade de percepção espacial (DEL GRANDE, 1994), assunto amplamente discutido nesse referencial.

Todos os sujeitos aceitaram dar continuidade ao estudo de caso e ter a pesquisadora inserida em suas aulas de Geometria. Quando se realizou o convite, uma das respostas obtidas foi: "É até melhor! [risos]. Porque assim, a entrevista deixa a gente um pouco surpresa. Então pode ser que saindo daqui eu vou me lembrar de muitas coisas que eu deveria ter falado e não falei. Então aceito, sim" ( $\mathrm{P}_{1}$, Entrevista cedida ao autor 1, 2017). As aulas tiveram uma duração média de duas horas/aula e o número de aulas observadas variou, pois a pesquisadora facultou aos participantes a possibilidade de definição do tempo de duração de suas atividades.

A seguir, apresenta-se o Quadro 3 com a síntese das aulas observadas pela pesquisadora:

\begin{tabular}{|c|c|c|c|c|c|}
\hline $\begin{array}{c}\text { Sujeito } \\
\text { Ano }\end{array}$ & $\begin{array}{c}\mathbf{P}_{1-} \\
3^{\circ} \text { ano }\end{array}$ & $\begin{array}{c}P_{2-} \\
1^{0} \text { ano }\end{array}$ & $\begin{array}{c}\mathbf{P}_{3-} \\
2^{\circ} \text { ano }\end{array}$ & $\begin{array}{c}\mathbf{P}_{4-} \\
2^{\circ} \text { ano }\end{array}$ & $\begin{array}{c}P_{5-} \\
2^{\circ} \text { ano }\end{array}$ \\
\hline $\begin{array}{c}\text { Conteúdo } \\
\text { abordado } \\
\text { na aula }\end{array}$ & $\begin{array}{l}\text { Localização } \\
\text { espacial }\end{array}$ & $\begin{array}{l}\text { Formas geométricas bi/ } \\
\text { tridimensionais }\end{array}$ & $\begin{array}{l}\text { Formas } \\
\text { geométricas bi/ } \\
\text { tridimensionais }\end{array}$ & $\begin{array}{l}\text { Formas } \\
\text { geométricas bi/ } \\
\text { tridimensionais }\end{array}$ & $\begin{array}{c}\text { Formas } \\
\text { geométricas } \\
\text { tridimensionais. }\end{array}$ \\
\hline $\begin{array}{c}\text { Descrição } \\
\text { da } \\
\text { atividade/ } \\
\text { * Obser- } \\
\text { vação da } \\
\text { pesquisa- } \\
\text { dora }\end{array}$ & $\begin{array}{c}\text { Caça ao } \\
\text { tesouro } \\
\text { Semelhante } \\
\text { à atividade } \\
\text { proposta no } \\
\text { PNAIC. } \\
* \\
\text { Dificuldades } \\
\text { conceituais. }\end{array}$ & $\begin{array}{l}\text { Conceituação/Repetição } \\
\text { Desenho e manuseio de } \\
\text { massinha de modelar } \\
* \text { Dificuldades } \\
\text { conceituais. }\end{array}$ & $\begin{array}{l}\text { Proposta } \\
\text { fidedigna ao } \\
\text { caderno de } \\
\text { formação do } \\
\text { PNAIC. } \\
\text { * Dificuldades } \\
\text { conceituais. }\end{array}$ & $\begin{array}{c}\text { Exploração do } \\
\text { material, } \\
\text { associações } \\
\text { com outras } \\
\text { atividades. } \\
\text { Proposta de } \\
\text { atividade } \\
\text { semelhante a } \\
\text { do PNAIC. }\end{array}$ & $\begin{array}{c}\text { Proposta partiu } \\
\text { de atividades } \\
\text { presentes no } \\
\text { livro didático, } \\
\text { com } \\
\text { associações à } \\
\text { observação do } \\
\text { espaço da sala } \\
\text { de aula. } \\
\text { * Dificuldades } \\
\text { conceituais. }\end{array}$ \\
\hline
\end{tabular}

Quadro 3 - As aulas de Geometria dos sujeitos de pesquisa Fonte: Dados compilados pelas autoras (2017). 
Embora, anteriormente, tenham informado em seus discursos que desejariam que seus alunos fossem além da memorização das formas e classificação dos sólidos geométricos, suas formações discursivas nos momentos do preparo e execução das aulas indicaram o contrário. Das cinco participantes, apenas uma não focou sua aula em conceitos e nomenclaturas de sólidos bi e tridimensionais, conforme elucidado no Quadro 3.

Segundo aponta o sinal gráfico (*), no campo "descrição das atividades/ observação da pesquisadora", quatro participantes demonstraram dificuldades com o conteúdo quando, por exemplo, cometeram erros conceituais ao explicar os atributos definidores dos sólidos geométricos. Observou-se, também, que nenhuma participante propôs suas aulas interdisciplinarmente, fator extremamente enfocado como positivo na formação do PNAIC.

Tendo dado aos sujeitos tempo e espaço para reflexões a respeito de suas formações, suas ações pedagógicas e sobre a maneira com que os conteúdos abordados na formação continuada influenciaram sua maneira de entender o ensino de Geometria, foi proposto que avaliassem a formação do PNAIC nesse componente curricular, destacando os pontos positivos e negativos, bem como a autopercepção de participação de cada uma no programa.

Foi consenso entre as docentes que a formação do PNAIC foi positiva. De acordo com os discursos, os destaques ficaram em torno de: “[...] os exemplos de prática [...]” $\left(\mathrm{P}_{1}\right)$; “[...] tinha muitos exemplos, muita teoria, muito embasamento. Onde procurar, por que procurar; tinha a parte prática e a parte teórica" $\left(\mathrm{P}_{2}\right)$ (Entrevistas cedidas ao autor 1, 2017). Além desse fator marcante, mereceu destaque o fato de o curso também "[...] mostrar que o concreto, que a brincadeira, que o jogo, que o pegar, o manusear, ele tem que acontecer, principalmente no $1^{\circ}$ ano $[. .$.$] " \left(\mathrm{P}_{3}\right)$, bem como a "[...] troca de experiência mútua foi bem enriquecedora. Os livros escritos no PNAIC estão de uma forma clara que dá para o professor utilizar de uma forma tranquila" $\left(\mathrm{P}_{4}\right)$ e "[...] a gente fez bastante atividade prática, a gente estudou bastante, foi excelente" $\left(\mathrm{P}_{5}\right)($ Entrevistas cedidas ao autor 1$)$.

Tendo a questão das atividades práticas propiciadas pelo curso se destacado nas respostas, observaram-se traços de um ensino voltado ao pragmatismo. Com base no entendimento de que não há um discurso que não se relacione com os outros (ORLANDI, 2002) destacam-se, aqui, as marcas dos modelos formativos pautados nos ideais da racionalidade técnica, no qual "[...] a atividade profissional consiste na solução instrumental de um problema, feita pela rigorosa aplicação de uma teoria científica ou uma técnica" (SCHÖN, 1983, p. 21).

Visto por essa vertente, entende-se que os sujeitos desta pesquisa conferem assentimento aos enfoques das abordagens comportamentalistas em educação que, entre as décadas de 1960 e 1970, refletiam-se nas ações formativas e passaram a se alicerçar em uma base "científica" 
para a docência, gerando o entendimento de professor como "profissional técnico", ou seja, um profissional cuja habilidade básica era a de aplicar, em aula, os conhecimentos das ciências do comportamento (CONTRERAS, 2002; TARDIF, 2014).

Outros pontos importantes foram destacados, entre eles a troca de experiência $\left(\mathrm{P}_{4}\right)$ e o fato de as professoras terem estudado sobre algo importante para a sua prática $\left(\mathrm{P}_{5}\right)$. Essa possibilidade gerada pelo PNAIC mereceu destaque, pois permitiram que as participantes do curso demonstrassem seus saberes experienciais (TARDIF, 2014), suas representações e interpretações sobre as ações por elas desenvolvidas.

Gauthier et al. (2006, p.17) destacam que "[...] os elementos do saber profissional docente são fundamentais e podem permitir que os professores exerçam o seu ofício com muito mais competência". É necessário que se desvincule a formação docente (inicial ou continuada), daquilo que caracteriza o autor como "saberes sem ofício", no qual não se leva em conta o professor real, a sua sala de aula, seus contextos, mas idealizam um professor e criam teorias generalistas produzidas na academia, sem vínculo com a realidade.

De acordo com o mesmo autor, é preciso propor uma formação pautada em um "ofício feito de saberes", admitindo a existência de um repertório de conhecimentos próprios do ensino. Oportunizando, por exemplo, a troca entre os pares, sob as diferentes ações pedagógicas que exercem com a Geometria, poder-se-ia contribuir para o aperfeiçoamento da prática docente, fato destacado como positivo por uma participante, mas que ocorreu de forma aligeirada, em sua percepção, na formação do PNAIC.

Este aligeiramento deixou lacunas na formação e está associado ao fato apontado por um dos sujeitos: o tempo de duração do curso. Tendo a formação em Geometria sido ministrada em apenas 12 horas, de um total de 100 horas da formação em Matemática, tornou-se difícil que os participantes tivessem "voz", uma vez que as ações giraram em torno da execução das atividades propostas no caderno de formação e partilha dos resultados. "[...] Acho que, assim, o estudo do caderno deveria ter sido em tempo maior, não em apenas um encontro como foi; um ou dois encontros" $\left(\mathrm{P}_{1}\right.$, Entrevista cedida ao autor 1, 2017).

A maioria das participantes escutadas $\left(\mathrm{P}_{1}, \mathrm{P}_{3}, \mathrm{P}_{4}\right.$ e $\left.\mathrm{P}_{5}\right)$ consideraram que o fato de ter ido aos encontros e colocado "[...] em prática o que aprendeu no PNAIC, até hoje, mesmo dois anos após a formação" ( $\mathrm{P}_{1}$, Entrevista cedida ao autor 1, 2017), confere uma boa avaliação quanto a sua formação.

Ao se avaliarem, as participantes não consideraram as dificuldades que ainda possuem referentes ao ensino de Geometria. Ao longo da entrevista, relataram dificuldades com o conteúdo, mas, no momento em que foram convidadas a refletir sobre os motivos para as 
lacunas nessa formação, não avançaram no sentido de uma argumentação mais consistente.

\section{Considerações finais}

É importante que surjam novas propostas de formação continuada em relação à Geometria; que sejam organizadas, planejadas e desenvolvidas de modo a atender também às necessidades formativas dos professores, considerando as problemáticas aqui apontadas, bem como o contexto de trabalho e a articulação entre os conhecimentos teóricos e práticos, para que ocorra um aprofundamento dos saberes necessários ao ensino de Geometria nos Anos Iniciais.

A trajetória educacional dos sujeitos em relação à aprendizagem de Geometria demonstrou-se insuficiente, indo ao encontro das discussões teóricas que já sinalizavam um abandono com a temática anteriormente à homologação do PCN de Matemática (BRASIL, 1997). Mesmo as professoras tendo declarado que buscam os conceitos e recursos para aulas em fontes diversas, percebeu-se que essa lacuna formativa deixou marcas que, somadas às concepções de ensino de cada uma e às ideologias cristalizadas dos cursos de formação continuada ao longo de anos, não foram capazes de mudar de forma significativa um cenário que requer urgência, pois ninguém ensina o que não domina. Neste sentido, se outras medidas formativas não forem implantadas e fomentarem novas discussões sobre essa temática, o passo alcançado com o curso oferecido pelo PNAIC poderá retroceder e, mais uma vez, o ensino de Geometria não ganhará destaque nos planejamentos curriculares e nas aulas dos Anos Iniciais.

Um fato atrelado ao ensino dos conteúdos geométricos e à formação docente, que se destacou nesta pesquisa, foi que a formação inicial em Pedagogia não garantiu o conhecimento necessário em Geometria, para lecionar para os Anos Iniciais do Ensino Fundamental, corroborando um "círculo vicioso" (Figura 1), no qual quem não aprende, não ensina, e contribuindo para que esse conteúdo perdesse seu destaque nas ações educativas. Conclui-se, neste sentido, que as lacunas formativas oriundas da formação inicial também são determinantes para a busca por cursos de formação continuada, como ocorreu com o PNAIC de Matemática, porém não são suficientes para subsidiar a apropriação de conceitos abandonados em décadas de estudos. 


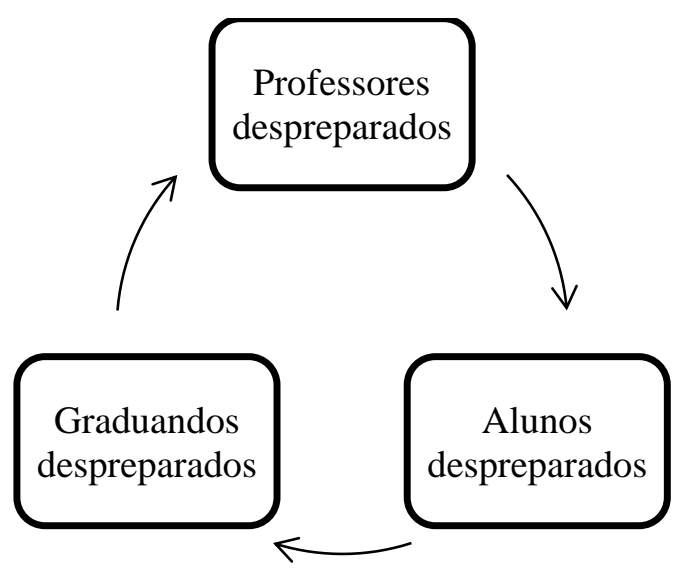

Figura 1 - Ciclo histórico do ensino de Geometria nos Anos Iniciais Fonte: BARBOSA (2017, p. 77).

Desta forma, a condição de produção, na qual esses discursos se firmaram, demonstrou que seus sujeitos vivenciaram o período de abandono do ensino de Geometria no Ensino Fundamental I e, por consequência, sentem e demonstram dificuldades com a temática. Assim, por insegurança ou desconhecimento em relação ao assunto a ser ensinado, passam as dificuldades adiante.

Sobre a autoavaliação em relação ao PNAIC e à participação dos sujeitos no curso, percebeu-se também a significância conferida às formações que exploram a parceria teoria e prática. Ou seja, os sujeitos aprovam as formações que explorem os conceitos teóricos e apresentem situações em que estas teorias possam manifestar-se no ensino em sala de aula. Neste sentido, evidenciam-se os traços de uma formação compreendida muito mais em relação à racionalidade técnica do que a crítica. Os termos "prática" e "práticas", cujo efeito de sentido faz menção a atividades concretas, manipuláveis, que fujam das aulas expositivas e que possibilitem um novo recurso didático, destacaram-se em quase todas as respostas, evidenciando possíveis marcas ideológicas.

A iniciativa da formação do PNAIC em abordar o ensino de Geometria foi apenas o primeiro passo de muitos que devem ser dados rumo à superação das dificuldades conceituais e o quase abandono desse tema nos Anos Iniciais. O cenário apontado na pesquisa (BARBOSA, 2017) indica que mudanças devem ocorrer, a começar pela formação inicial. Também devem ser formulados novos cursos de formação continuada, com carga horária ampliada, partindo das lacunas apontadas por este e outros estudos, que demonstram que os professores, entre outras, possuem dificuldades conceituais com a Geometria e não apenas metodológicas.

Este trabalho centrou-se em oferecer contribuições para a compreensão da relação entre a trajetória educacional dos professores sobre o ensino de Geometria e os impactos da formação continuada oferecida, sobre esse conteúdo, no Pacto Nacional da Alfabetização na 
Idade Certa (PNAIC), diante de um panorama educacional nacional que levou em conta as condições de produção do discurso, bem como algumas influências econômicas, sociais, políticas e ideológicas, presentes no cenário das formações continuadas de professores e no ensino de Geometria ao longo de anos.

Os resultados apresentados apontam que, após a participação na formação do PNAIC, as professoras envolvidas sinalizaram discretas mudanças em suas ações pedagógicas, contudo ainda possuem dificuldades conceituais, bem como continuam "presas" aos modelos formativos que exploram rapidamente a teoria e envolvem-nas no entendimento de que os modelos de ações práticas e exemplificações de novos recursos didáticos são mais significativos ao trabalho docente.

No entanto, defendemos que a articulação da teoria e da prática deva ir além da transposição de um conceito para a ação pedagógica: ela deve possibilitar ao professor refletir sobre sua realidade educacional e aprofundar-se em buscas conceituais e discussões teóricas que lhes possibilite sanar as suas lacunas de ensino e favorecer a aprendizagem.

\section{Referências}

ALMEIDA, M. J. P. Entrevista e representação na memória do ensino de Ciências: uma relação com a concepção de linguagem. In: NARDI, R. (Org.). A pesquisa em Ensino de Ciências no Brasil: alguns recortes. 2. ed. São Paulo: Escrituras, 2007. p. 117-130.

BARBOSA, A. P. R. Formação continuada de professores para o ensino de Geometria nos anos iniciais: um olhar a partir do PNAIC. 2017.180 f. Dissertação (Mestrado em Educação para Ciência) Faculdade de Ciências, Universidade Estadual Paulista "Júlio de Mesquita Filho", Bauru, 2017.

BRANDÃO, H. N. Introdução à Análise de Discurso. 6. ed. Campinas: Editora da Unicamp, 2002.

BRASIL. Ministério da Educação. Secretaria de Educação Fundamental. Parâmetros Curriculares Nacionais: Matemática. Brasília: MEC/SEF, 1997. 142p.

BRASIL. Ministério da Educação. Portaria n 1458 de 14 de dezembro de 2012. Define categorias e parâmetros para a concessão de bolsas de estudo e pesquisa no âmbito do Pacto Nacional pela Alfabetização na Idade Certa. Diário Oficial da União, Brasília, DF, 18 de dez de 2012.

BRASIL. Secretaria de Educação Básica. Diretoria de Apoio à Gestão Educacional. Pacto Nacional pela Alfabetização na Idade Certa: Apresentação / Ministério da Educação, Secretaria de Educação Básica, Diretoria de Apoio à Gestão Educacional. Brasília: MEC, SEB, 2014.

BOGDAN, R.; BIKLEN, S. Investigação Qualitativa em Educação: uma introdução à teoria e aos métodos. Coleção Ciências da Educação. 1. ed. Portugal, Porto Editora, 1994.

CONTRERAS, J. A autonomia dos professores. 2. ed. São Paulo: Cortez, 2002.

CORTELA, B. S. C. Formação inicial de professores de Física: fatores limitantes e possibilidades de avanços. 2011. 289 f. Tese (Doutorado em Educação para Ciências) - Faculdade de Ciências, Universidade Estadual Paulista "Júlio de Mesquita Filho", Bauru, 2011. 
DEL GRANDE, J. J. Percepção espacial e geometria primária. In: LINDQUIST, M. M; SHULTE, A. P. Aprendendo e pensando geometria. Trad. Hygino H. Domingues. 1. ed. São Paulo: Atual, 1994. p. 156-167.

ESTRELA, A. Teoria e prática de observação de classes: uma estratégia de formação de professores. 4. ed. Porto: Porto, 1994.

FONSECA, M. C. F. R. et al. O ensino de Geometria na escola fundamental: três questões para a formação do professor dos ciclos iniciais. 1. ed. Belo Horizonte: Autêntica, 2002.

GATTI, B. A. Análises das políticas públicas para a formação continuada no Brasil, na última década. Revista Brasileira de Educação, Campinas, v. 13, n. 37, p. 57-70, jan./abr. 2008.

GATTI, B. A. Formação de professores no Brasil: características e problemas. Educação Sociedade, Campinas, v. 31, n. 113, p. 1355-1379, out./dez. 2010.

GAUTHIER, et al. Por uma teoria da pedagogia: pesquisas contemporâneas sobre o saber docente. 3. ed. Ijuí: Unijuií, 2006.

LORENZATO, S. A. Por que não ensinar Geometria? Educação Matemática em Revista, Blumenau: SBEM, ano III, n. 4, p. 3-13, 1995.

LORENZATO, S. A. Para aprender matemática. 1. ed. Campinas: autores associados, 2010.

MANDARINO, M. F. Objetivos do ensino de Geometria no processo de alfabetização. Geometria no ciclo da alfabetização (Salto para o futuro), Rio de Janeiro, Ano XXIV, n. 7, p. 9-15, set. 2014.

MELLO, G. N. Formação Inicial de professores para a educação básica: uma (re)visão radical. Revista São Paulo Em Perspectiva, São Paulo, n. 14 (1), p. 98-110, 2000.

NACARATO, A. M. Educação Continuada sob a perspectiva da Pesquisa-ação: currículo em ação de um grupo de professoras ao aprender ensinando Geometria. 2000. 323 f. Tese (Doutorado em Educação Matemática) - Faculdade de Educação, Universidade Estadual de Campinas, Campinas, 2000 .

ORLANDI, E. P. Análise do Discurso: Princípios \& Procedimentos. 4. ed. Campinas, SP: Pontes, 2002.

ORLANDI, E. P. Educação e Sociedade: o discurso pedagógico entre o conhecimento e a informação. ALED, Venezuela, v. 16, n. 2, p. 68-80, 2016.

PASSOS, C. L. B.; NACARATO, A. M. O ensino de geometria no ciclo de alfabetização: um olhar a partir da provinha Brasil. Revista Educação Matemática Pesquisa, São Paulo, v. 16, n. 4, p. 1147$1168,2014$.

PAVANELLO, R. M. O abandono do ensino de geometria no Brasil: causas e consequências. Zetetiké, Campinas, v. 1, n. 1, p. 7-17, 1993.

PIROLA, N. A. Um estudo sobre a formação dos conceitos de triângulo e paralelogramo em alunos de $1^{\circ}$ grau. 1995.108 f. Dissertação (Mestrado em Educação) - Faculdade de Educação, Universidade Estadual de Campinas, Campinas, 1995.

PIROLA, N. A. Práticas de Ensino de geometria: algumas experiências com o desenvolvimento e localização de pessoas/objetos no mundo físico. Geometria no ciclo da alfabetização (Salto para o 
futuro), Rio de Janeiro, Ano XXIV, Boletim 7, p. 16-22, set. 2014.

SCHÖN, D. The reflective practitioner. 1. ed. New York: Basic Books, 1983.

TARDIF, M. Saberes docentes e a formação profissional. 17. ed. Petrópolis: Vozes, 2014.

Submetido em 06 de Junho de 2017. Aprovado em 16 de Janeiro de 2018. 